Journal of Child and Adolescent Trauma - in press

Accepted: 22.1.2017

\title{
Understanding the long-term effects of childhood adversities: Beyond diagnosis and abuse.
}

Professor John Read [corresponding author]

School of Psychology

University of East London

Stratford Campus

London E15 4LZ

UK

+44(0)2082234943

john@uel.ac.uk

\section{Rachael Mayne}

Great Ormond Street Hospital for Children

London WC1N 3JH

UK

Running title: Childhood adversities: Beyond diagnosis and abuse.

Keywords: child maltreatment, child abuse, child neglect, bullying, loss, domestic violence, psychiatric diagnoses, psychiatric symptoms. 


\begin{abstract}
Aims: Studies of the effects of childhood adversities often use psychiatric diagnoses and focus on physical or sexual abuse. This study explored relationships between a broader range of adversities and both diagnoses and specific symptoms.
\end{abstract}

Methods: The files of 217 child and adolescent mental health service users were audited. Information regarding 14 adverse childhood experiences, 20 diagnoses and 38 symptoms was analysed.

Results: Only two diagnoses (Psychosis and Oppositional Defiant Disorder) were predicted by mean number of adversities. However, the symptom clusters indicative of six diagnoses were related to one or more childhood adversities. Strong specific relationships were found between sexual abuse and hyperarousal, parental substance abuse and rule violation, and loss and avoidance/numbing. Mean number of adversities predicted six specific symptoms as well as global functioning, risk to self, and risk to others. Parental mental health, a proxy for genetic influence, was unrelated to all diagnoses, all symptom clusters and all but one of the 38 symptoms.

Conclusions: Understanding the complex nature of the effects of childhood adversities are constrained by focusing on diagnoses and a restricted range of adversities. The need to take a full psychosocial history in child and adolescent mental health services, and the implications for primary prevention, are discussed.

Keywords: Child maltreatment, child abuse, child neglect, bullying, loss, domestic violence, psychiatric diagnoses, psychiatric symptoms. 
Understanding the effects of childhood adversities: Beyond diagnosis and abuse

Research has demonstrated that adverse events and circumstances can have important negative effects on psychological, social and biological development during childhood and adolescence (Briscoe-Smith \& Hinshaw, 2006; Fergusson \& Horwood, 1999; Maguire et al., 2015; Meller, Kuperman, McCullough, \& Shaffer, 2016; Teicher \& Sampson, 2016). The literature investigating the extent and nature of those effects inevitably deploys varying definitions and types of adversity as well as varying types and specificity of outcomes. This has led to variation in the findings about the overall strength and pervasiveness of the relationship between childhood adversity and negative outcomes. It has also led to inconsistency in conclusions about which specific negative outcomes are related to adversity in general and to which adversities in particular.

Furthermore, professional membership can influence research design and interpretation of findings. Psychiatry, for instance, tends to use diagnoses, rather than behaviours or emotional states, as outcome measures; and also tends to prioritise bio-genetic aetiological factors over psycho-social factors (Nigg \& Craver, 2014). A popular psychiatry textbook (Sadock \& Sadock, 2005; 2014) makes no mention of any childhood adversities when explaining the aetiologies of Early Onset Bipolar Disorder, Learning Difficulties, Autism, or Obsessive Compulsive Disorder but states that childhood adversity is definitely a causal factor for Conduct Disorder, Oppositional Defiant Disorder and, of course, PTSD. For example, the 2014 edition's section on Conduct Disorder not only argues that "socioeconomically deprived children are at higher risk" and that "parental psychopathology, child abuse and negligence often contribute to conduct disorder" but goes on to identify the intergenerational nature of these processes: "many such parents were scarred by their own upbringing and tend to be abusive, negligent, or engrossed in getting their own needs met" 
(Sadock \& Sadock, 2014, p. 95). Some diagnostic entities were not thought to be related to childhood adversity in 2005 but were by 2014, including Depressive Disorder, Generalised Anxiety Disorder, and Separation Anxiety. By 2014 it was also acknowledged that "children and adolescents with schizophrenia are more likely to have a premorbid history of social rejection" (Sadock \& Sadock, p. 167).

The textbook's position on ADHD is complex. The 2005 edition devoted 20 times more space to biological causes than to "environmental factors", most of which were biological, such as lead exposure, delivery complications and maternal smoking during pregnancy. The textbook states: "For children who live in chronically stressful multiproblem circumstances it is difficult to determine whether the symptoms reflect expression of underlying anxiety or depression, a problem with parenting or socialization, a genetically influenced biological problem, or some interaction with a number of these factors,' (Hechtman, 2005, p. 3186). By 2014 we read that "Stressful psychic events, disruption of family equilibrium, and other anxiety-inducing factors contribute to the initiation and perpetuation of ADHD", but that "ADHD is believed to be largely transmitted genetically", and that "socioeconomic status does not seem to be a predisposing factor" (p. 80), despite evidence to the contrary (Nigg \& Craver, 2014; Russell et al., 2014).

Some studies that use diagnoses as outcome measures have found relationships with one or more childhood adversities, typically sexual or physical abuse. PTSD and ADHD may be the two most commonly diagnosed disorders in children with a history of abuse (McLeer, Deblinger, Henry, \& Orvaschel, 1992; Weinstein et al., 2000). A large proportion of children who have experienced abuse and maltreatment develop PTSD (Briscoe-Smith \& Hinshaw, 2006; Weinstein et al., 2000). Research investigating children with a history of maltreatment have also consistently found higher than expected rates of ADHD (Endo, Sugiyama, \& Someya, 2006; Merry \& Andrews, 1994; Stern, Lynch, Oates, Otoole, \& Cooney, 1995; 
Webster, 2001). Other diagnoses that are common among children with a history of maltreatment are anxiety, depression, and dissociative disorders (Endo et al., 2006; Merry \& Andrews, 1994; Stern et al., 1995). A review of 36 studies found that:

Across the majority of studies, conduct disorder was significantly and directly related to child sexual abuse, especially repeated sexual molestation and abuse involving penetration. The association between child sexual abuse and conduct disorder was not confounded by other risk factors, such as gender, socioeconomic status, school achievement, substance problems, physical abuse, parental antisocial behaviour or substance problems, parent-child relationships, and family disruption, conflict, or violence. Evidence for a significant interactive effect between child sexual abuse and monoamine oxidase A gene on conduct disorder was scant. (Maniglio, 2015, p. 241). Other studies of diagnoses, however, have not found the relationships noted above. A study of 295 children using a psychiatric outpatient clinic found that 'polyvictimization' was related to severe externalizing problems and psychosocial impairment, but unrelated to any diagnosis other than PTSD (Ford, Wasser, \& Connor, 2011). Similarly, among 397 inpatient child psychiatry admissions, 'complex trauma' (defined as physical or sexual abuse with multiple perpetrators, extensive out-of-home placement and severe parental impairment) was related to severity of behavioural problems and to lower body mass index, but not to any psychiatric diagnoses (Ford, Connor, \& Hawke, 2009).

Many studies avoid diagnoses and focus instead on measureable behavioural or emotional outcomes. An early review concluded:

Problems most frequently associated with physical abuse include aggressive behaviour, social maladjustment, low self-esteem, and developmental delays. Neglected children are often significantly delayed in mental, motor, language and social development. Depression, actual or attempted suicide, and promiscuous 
behavior are the most commonly reported problems of sexually abused children"

(McLaren \& Brown, 1989, p. 1).

Most studies exploring whether there are specific relationships between certain types of adversity and specific types of behaviours or 'symptoms' have continued to focus on physical or sexual abuse, or, to a lesser but growing extent, neglect. Physical abuse, for example, has been specifically linked to externalizing behaviours (Briscoe-Smith \& Hinshaw, 2006). A population based study of over 14,000 adolescents found that although both the inattention and hyperactivity symptoms of ADHD were associated with neglect and physical abuse, only inattention was associated with sexual abuse (Ouyang et al., 2008). Emotional abuse, however, has been increasingly studied in the past decade (Maguire et al., 2015).

The current study sought to replicate studies that have used both diagnoses and more specific outcomes when exploring relationships between various adversities and outcomes (e.g. Ford et al., 2009; 2011) and hypothesised that, like the previous studies, the more specific outcome measures would be more informative. The study also, however, broadened the exploration beyond abuse and neglect to include a total of 14 types of childhood adversity and their relationships with 10 symptom clusters linked to 10 diagnoses and to 38 specific symptoms, as well as to risk to self, risk to others and overall functioning.

\section{Method}

\section{Participants}

The participants in the study were clients of a New Zealand child and adolescent mental health service [CAMHS]. This CAMHS is a publicly funded, community service that provides assessment and treatment for children and adolescents with a known or suspected mental health problem, usually at times of urgency or crisis. Of the 369 recently closed files that had been made available by the CAMHS, 217 were randomly selected from each of six age groupings in order to have an approximately even distribution of age. All of the 
participants had had face to face contact with at least one mental health staff member of the service during the period covered by the study.

\section{Measures}

The electronic clinical records of these 217 children and adolescents were analysed. Information from the records was recorded by hand on a purpose-designed three-page data collection form, based on the form used in a similar study (Read, Agar, Argyle, \& Aderhold, 2003). Information was recorded regarding demographics, symptoms, clinical diagnoses, risk assessments and global assessment of functioning (GAF). Diagnosis was recorded if a formal diagnosis was stated on the front page of the file. Some participants had more than one formal diagnosis and all of these were recorded and included in the data analyses.

Information was also gathered about childhood adversities, including: Physical Abuse; Sexual Abuse; Emotional Abuse; Emotional or Physical Neglect; Bullying; Exposure to Domestic or Family Violence; Parental Mental Health Problems; Parental Separation/Divorce; Exposure to Parental Discord; Parental Substance Abuse; Serious Physical Illness/Disability; Serious Family Illness; Poverty. The researchers' categorisation and recording of childhood adversities was based on a set of detailed definitions and subjected to an inter-rater reliability assessment.

\section{Procedures}

Each clinical file was read in its entirety. On average, each file took approximately 90 minutes to read and code, representing a total of 325 hours of data collection. Information was transferred verbatim onto the data collection sheet to avoid subjective interpretations on behalf of the investigators, particularly relating to symptoms and adversities. A Risk Assessment form was used in each participant's clinical file. In the form, 'risk to self' and 'risk to others' was rated as low, medium, or, high. This risk rating was recorded directly onto the data collection sheet. Due to the data being restricted to a review of electronic 
clinical records, what was considered a significant symptom or adversity was based on what the clinician, client, parents, and/or referrer perceived and reported, and what the clinician considered important enough to record in the file.

In order to assess inter-rater reliability, the two researchers independently entered the information from 20 data collection sheets into SPSS. An overall percentage of accuracy for symptoms and adversities was calculated. This was assessed by calculating the total number of errors for the coding of both 'yes' and 'no' for all symptoms and adverse childhood events, and then calculating an overall percentage of accuracy between the two researchers. This process was repeated three times, until the level of consistency at all levels was $97.0 \%$ for symptoms and $93.5 \%$ for adversities. The remaining data collection sheets were entered into SPSS using the refined definitions and rules, which were intentionally conservative so as to reduce the probability of false positives. While space does not permit all these rather lengthy definitions (available on request), some examples of entries in the medical records that did not meet the criteria for inclusion in the study, i.e. were not sufficiently clear, severe or frequent, follow.

Physical Abuse: "Bullied at school since intermediate"; "Hit and pushed by older sister at times as a child"; "Slapped by his father".

Sexual Abuse: "Suspected sexual abuse as a child by a male painter who came into the home"; "X had an unwanted sexual experience with male friend while intoxicated".

Witnessing Domestic or Family Violence: "Frequent arguments between family members"; "Lots of fighting in the family home".

Parental Mental Health Problems: "Mother believes that X's father is depressed"; "Mum was sad and cried a lot during pregnancy"; "Mum was burnt out while X was a toddler". 
Parental Discord: "Relationship issues [parents]"; "Parental conflict”; Friction in parents' relationship".

\section{Data analysis}

Thirty-eight symptoms were grouped into ten symptom clusters (comprised of between two and seven symptoms) based on the criteria for corresponding DSM-IV-R diagnostic categories. For example, there were three ADHD variables: Inattentiveness, Hyperactivity, and Impulsivity. Therefore, if a participant had all of the ADHD symptoms this would give an ADHD cluster score of 3. The other clusters, listed in Table 1, were for PTSD, Psychosis, Conduct Disorder, Oppositional Defiant Disorder, Mood Disorders, Anxiety Disorders, Eating Disorders, Learning Disorders, and Aspergers Syndrome.

\section{TABLE ONE ABOUT HERE}

Descriptive data (means, standard deviations, frequencies) were used to examine the sample characterises in terms of symptoms, diagnoses and childhood adversities.

Relationships involving categorical variables, such as between diagnoses and gender, or specific adversity, were examined using chi-square tests of association $\left(X^{2}\right)$, or, where expected cell sizes were less than five, Fisher's exact test. Relationships between continuous variables, such as total number of adversities, GAF scores and symptom cluster scores, were tested using the Pearson correlation coefficient $(r)$. Group mean differences were examined using independent sample t-tests (two-tailed).

Because of the large number of analyses, results were only considered statistically significant if the $p$-value was less than .01, so as to reduce the probability of Type 1 errors, i.e. false positives.

\section{Results}




\section{Sample characteristics}

Of the 217 participants in the study, 52.1\% were female. The participants ranged in age from two to 18 years, with a mean of $12.39(\mathrm{SD}=4.18)$. Just over half $(52.5 \%)$ were 13 years or younger. The majority (58.5\%) were European, $15.7 \%$ were Maori, $11.5 \%$ were Asian, $8.8 \%$ were Pacific Islander, and 5.5\% were of 'other' ethnicity.

\section{Diagnoses}

Most $(80.2 \%)$ of the participants were given at least one formal diagnosis, $21.2 \%$ had two and $11.9 \%$ had three or more. The 20 diagnoses allocated at least five times are listed in Table 2. The most frequent were Depression NOS - 27 (12.4\%) and ADHD - 25 (11.5\%).

Females had significantly higher rates of Major Depressive Disorder $\left(X^{2}=5.8, p=\right.$ $.002)$ and Depression NOS $\left(X^{2}=8.0, p=.007\right)$. Males had higher rates of ADHD $\left(X^{2}=\right.$ $14.9, p<.001)$, and Aspergers Syndrome $\left.X^{2}(1, N=216)=15.20, p<.001\right)$.

\section{TABLE TWO ABOUT HERE}

\section{Childhood adversities}

The average number of adverse events recorded in files was $3.30(S D=2.30)$. The majority $(192,88.5 \%)$ had at least one of the 14 childhood adversities recorded. Twenty one (9.7\%) had only one adversity, 44 (20.3\%) two adversities, 36 (16.6\%) three adversities, 35 (16.1\%) four adversities, 20 (9.2\%) five adversities, and $36(16.6 \%)$ had six or more.

The frequencies with which the 14 adversities were recorded were: Parental Mental Health Problems - 90 (41.5\%); Loss - 84 (38.7\%); Divorce - 77 (35.5\%); Emotional Abuse 75 (34.6\%); Bullying - 71 (32.7\%); Physical Abuse - 63 (29\%); Parent Discord - 47 (21.7\%); Parental Substance Abuse - 40 (18.4\%); Neglect - 33 (15.5\%); Sexual Abuse - 30 (13.8\%); Domestic Violence - 27 (12.4\%); Serious Physical Illness/Disability - 19 (8.8\%); Serious 
Family Illness - 14 (6.5\%); Poverty - 16 (6\%). There were 30 cases of "other" adversities, which were excluded from analyses because of low numbers.

Females had higher rates of sexual abuse $\left(X^{2}=8.3, p=.004\right)$ and emotional abuse $\left(X^{2}=7.8, p=.005\right)$ than males.

\section{Relationship between adversities, symptoms, and diagnoses}

Adversities and diagnoses. Two of the 20 clinical diagnoses, psychosis and ODD, were significantly related to the mean number of adversities. Participants with a diagnosis of psychosis had a higher average number of adversities (7.2) than participants without a diagnosis of Psychosis (3.2), $(t[215]=3.98, p<.001)$. Participants diagnosed with ODD had a higher average (6.4) than those without this diagnosis $(3.2),(t[215]=3.12, p=.002)$.

Three diagnoses, Psychosis, ODD and PTSD, were significantly related to a specific childhood adversity. A diagnosis of Psychosis was specifically associated with neglect $\left(X^{2}=\right.$ $16.7, p=.002)$. A diagnosis of ODD was specifically associated with divorce $\left(\mathcal{X}^{2}=9.3, p=\right.$ .005). A diagnosis of PTSD was specifically associated with sexual abuse $\left(X^{2}=32.2, p<\right.$ $.001)$

Adversities and symptom clusters. Three of the ten symptom clusters were significantly related to number of adverse events: Mood symptoms $(r=.30, \mathrm{p}<.001)$; CD symptoms $(r=.24, \mathrm{p}<.001)$; and Psychosis symptoms $(r=.24, \mathrm{p}<.001)$.

These three symptom clusters, and three others, were significantly related to one or more specific adversities. Two adversities, Sexual Abuse and Emotional Abuse, were related to more than one symptom cluster. Mood symptoms were related to Sexual Abuse $\left(\chi^{2}=\right.$ $17.4, p=.001)$ and Emotional Abuse $\left(X^{2}=18.2, p=.001\right)$; Psychosis symptoms to Parental Substance Abuse $\left(X^{2}=14.3, p=.003\right)$; and CD symptoms to Domestic Violence $\left(X^{2}=\right.$ $15.8, p=.002)$. In addition, PTSD symptoms were related to Sexual Abuse $\left(X^{2}=18.0, p<\right.$ $.001)$ and to Loss $\left(X^{2}=16.6, p=.001\right)$; ODD symptoms to Physical Abuse $\left(X^{2}=12.5, p=\right.$ 
$.002)$ and Neglect $\left(X^{2}=9.4, p=.008\right)$; and Eating Disorder symptoms to Emotional Abuse $\left(X^{2}=14.6, p=.002\right)$.

Adversities and specific symptoms. Seven of the 38 specific symptoms were significantly related to mean number of adversities: Deceitfulness/Theft (4.3 vs. $3.1 ; t$ [215] $=2.89, \mathrm{p}=.004) ;$ Low Mood (3.8 vs. 2.8; $t[215]=3.27, \mathrm{p}=.001)$; Other Depressive Symptoms $(3.8$ vs. $2.6 ; t[215]=3.81, \mathrm{p}<.001)$; Mania $(5.9$ vs. $3.2 ; t[215]=3.06, \mathrm{p}=.002)$; Delusions (5.4 vs. $3.2 ; t[215]=3.38, \mathrm{p}=.001)$; Disorganised Speech $(6.5$ vs. $3.2 ; t[215]=$ $3.56, \mathrm{p}<.001)$; and Negative Psychotic Symptoms $(10.0$ vs. $3.2 ; t[215]=4.31, \mathrm{p}<.001$.

Table 1 shows that seven specific symptoms were significantly related to one adversity; and four specific symptoms were significantly related to two adversities. Some examples follow. The CD symptom Serious Violation of Rules was significantly related to both Parental Substance Abuse $\left(X^{2}=15.5, p<.001\right)$ and Physical Abuse $\left(X^{2}=9.2, p=\right.$ $.002)$. Low mood was related to both Sexual Abuse $\left(X^{2}=9.1, p=.003\right)$ and Emotional Abuse $\left(X^{2}=11.0, p=.001\right)$. The PTSD symptom Hyperarousal was related to Sexual Abuse $\left(X^{2}=33.7, p<.001\right)$. The Psychosis symptom Disorganised/Catatonic Behaviour was related to Neglect $\left(X^{2}=11.9, p=.005\right)$. The ADHD symptom of Hyperactivity was related to Domestic Violence $\left(X^{2}=12.2, p=.002\right)$.

\section{Adversities and overall functioning}

The Global Assessment of Functioning (GAF) measure (estimated for only 92 participants in the medical files)[A1] was significantly correlated with total number of adversities $(r=.34, \mathrm{p}<.001)$. No individual adversity was independently related to GAF.

\section{Adversities and risk}

Table 3 shows that the mean number of adversities was significantly correlated to both Risk to Self $(r=.31, \mathrm{p}<.001)$ and Risk to Others $(r=.23, \mathrm{p}<.006)$. Risk to Others was 
specifically related to Domestic Violence $\left(X^{2}=9.1, p=.007\right)$ and Emotional Abuse $\left(X^{2}=\right.$ $9.1, p=.007)$. No individual adversity was significantly related to Risk to Self.

\section{TABLE THREE ABOUT HERE}

\section{Discussion}

Firstly, this study confirms many others (summarised in the introduction) that have, over the past two decades, repeatedly found that a broad range of adverse events and circumstances in childhood are predictive of a broad range of negative outcomes later in childhood and in adolescence, including not only a range of specific behaviours and feelings, but global functioning and risk to self and others. It seems that efforts to understand the mental health problems, including suicidality, of children and adolescents, from a narrow biomedical perspective are, or should be, behind us.

\section{The value of detailed studies}

Secondly this study suggests that when trying to establish, or understand, the relationships between adversities and distress in childhood and adolescence, psychiatric diagnoses can be limiting. If the current study had relied exclusively on diagnosis, as many studies still do, the problems of children with 18 of the 20 diagnoses would have been deemed irrelevant to overall level of adversity. However, a focus on the specific behaviours and feelings that are sometimes categorised as symptoms, and on a broader than usual range of adversities, reveals that 11 of the specific symptoms of a range of diagnoses were significantly related to one or more adversities. For example, besides replicating the established relationship between sexual abuse and the symptoms of re-experiencing and hyperarousal that are typically associated with PTSD, we find that another PTSD symptom, avoiding and numbing, is associated not with sexual abuse but with loss. We also see 
relatively new, intriguing, findings such as the rule violation symptom of Conduct Disorder being predicted not just by physical abuse, but, even more strongly, by parental substance abuse.

Thirdly, a focus only on the most studied adversities, such as sexual and physical abuse, would have missed important pieces of the puzzle for this sample of young people. For example, domestic violence predicted both hyperactivity, an ADHD 'symptom, and the aggression symptom of conduct disorder. Within psychosis, catatonic/disorganised behaviour was predicted by child neglect, and negative symptoms were predicted by growing up in poverty.

\section{Informing aetiological theory}

This more detailed approach, covering broad ranges of specific adversities and specific behavioural and emotional outcomes, may also inform our understanding of the processes by which the outcomes develop. This approach has proved valuable when exploring pathways linking specific childhood adversities to specific psychotic symptoms and experiences (Bentall et al., 2014; Longden, Sampson, \& Read, 2016; Read, 2013). In one study, of 13 different types of childhood adversity, the most predictive of psychosis symptoms were poverty and the rarely studied variable of fostering or adoption (Longden et al., 2016).

In the current study the sample size may not be large enough and the design sufficiently robust (see Limitations) to reach definitive conclusions about causal relationships. Nevertheless, it does raise some interesting questions. Is it possible, for instance, that the very strong relationship between the substance abuse of parents and the rule violation of their children indicates a role for social learning rather than just seeing the rule breaking as a symptom of a bio-genetically based mental illness called conduct disorder? Should we wonder about the same issue when we find a relationship between domestic 
violence and the 'conduct disorder' symptom of aggression? We also find that the 'negative symptoms' of 'schizophrenia', until recently thought to be the most bio-genetically based of all 'mental illnesses', are powerfully predicted by not only by overall number of adversities in general, but also specifically by growing up in poverty. Parental mental health, a potential proxy for genetic influence (intergenerational transmission is no proof of genetic involvement), was unrelated to all the diagnoses, all the symptom clusters and all but one (avoidance/numbing) of the 38 specific symptoms.

It may also be particularly noteworthy that not only were both suicide risk and risk to others predicted by overall level of adversity suffered, but risk to others was specifically linked to emotional abuse and domestic violence, another relationship that might have been missed a decade or more ago with our greater focus then on sexual and physical abuse.

\section{Practical implications}

There are two final, perhaps obvious, implications of these kinds of findings. The first is the need for routine inquiry about a broad range of adversities in child and adolescent mental health services. Just as it is helpful in a research setting to look behind hypothesised diagnoses it can be very important, when planning treatment or support strategies, to explore specific difficulties in the child's real world, and the factors that caused and maintain them. There is a need for comprehensive initial assessments that gather information from a variety of sources such as the child or adolescent, their family, school, and other relevant services involved with the child. Comprehensive assessment is crucial in identifying the complex needs, areas of risks, and available resources of these children, their families, and professionals involved in their wider system (Kisiel, Fehrenback, Small, \& Lyons, 2009). Furthermore, a thorough assessment ensures that treatment is tailored to meet the needs of the child and their family. The few studies that have been conducted in this area have all, to the best of our knowledge, been in adult services. They have all found inadequate levels of both 
inquiry about adversities and response to disclosure (Agar \& Read, 2002; Agar, Read, \& Bush, 2002; Hepworth \& McGowan, 2013; Posner, Eilenberg, Friedman, \& Fullilove, 2008; Read, Sampson, \& Critchley, 2015; Rossiter et al., 2015). Agency policies on this issue will probably be ineffective unless the barriers to asking and responding are identified and addressed (Young, Read, Barker-Collo \& Harrison, 2001), and training is introduced on how, when and how to ask, and how to respond (Read, Hammersley, \& Rudegeair, 2007). Any positive changes that result are more likely to be maintained if there have simultaneously been to nurture or create a 'trauma-informed' framework for the service (Bateman, Henderson, \& Kezelman, 2013; Muskett ,2014; Rose, Freeman, \& Proudlock, 2012).

The second is the need for primary prevention programmes targeted at all the adversities in childhood that we know can have long-lasting effects on our development through childhood and adolescence into adulthood, and, when we become parents, into the next generation (Albee, 1985). A focus on the first three to five years of life would seem to be the most effective approach (Allen, 2011; Perry, 2013).

\section{Future research}

Replication of this study with a much larger sample would be desirable. Research into the extent to which child and adolescent mental health services are asking about a broad range of adverse events, and responding appropriately to positive responses is urgently needed.

\section{Limitations and strengths of the study}

A cross-sectional audit is not as robust as a prospective design in terms of establishing causal relationships. This study only included child and adolescent clients at a New Zealand CAMHS so the findings may not be generalizable to all children and adolescents. The findings are based on information obtained from pre-existing clinical records and the quality, quantity, and nature of information recorded will have varied from case to case. The 
information in the clinical records may not have represented the true rates of adverse events experienced by clients.

The researchers, however, went through a stringent inter-rater reliability check process. This helped to reduce any potential rater bias of what was included in the study as a symptom or adverse event. Furthermore, the files used in the study offered very detailed and comprehensive information regarding the young person's presenting problems, background history, and treatment plan. Every file was read in its entirety, including clinical notes, forms, and assessment sheets. This provided a rich and comprehensive source of data.

\section{Compliance with Ethical Standards}

Procedures were in accordance with the 1964 Helsinki declaration and its later amendments. Permission for the study was given by the Ethics Committees of the University of Auckland and the local District Health Board. The study was an audit and did not, therefore, require signed consent from the individual participants or their parents. The participants' data was depersonalised in the data collection process. The names of the clients were not recorded on the data collection sheets. 


\section{References}

Agar, K. \& Read, J. (2002). What happens when people disclose sexual or physical abuse To staff at a community mental health centre? International Journal of Mental Health Nursing, 11, 70-79. doi: 10.1046/j.1440-0979.2002.00230.x

Agar, K., Read, J., \& Bush, J. (2002). Identification of abuse histories in a community mental health centre: The need for policies and training. Journal of Mental Health, 11, 533-543. doi: 10.1080/09638230020023886

Albee, G. (1985). The argument for primary prevention. Journal of Primary Prevention, 5, 213-219. Retrieved from http://link.springer.com/article/10.1007\%2FBF01324537\#page-1

Allen, G. (2011). Early intervention: The next steps. London: H.M.Government.

Bateman, J., Henderson, C. \& Kezelman, C. (2013). Trauma-informed care and practice: Towards a cultural shift in policy reform across mental health and human services in Australia. Rozelle, NSW: Mental Health Coordinating Council. Retrieved from http://mhcc.org.au/media/34556/ch-a_national_strategic_direction-ticp-forumpresentation.pdf

Bentall, R., de Sousa, P., Varese, F., Wickham, S., Sitko, K., Haarmans, M., \& Read, J. (2014). From adversity to psychosis: pathways and mechanisms from specific adversities to specific symptoms. Social Psychiatry and Psychiatric Epidemiology 49, 1011-1022. doi: 10.1007/s00127-014-0914-0

Briscoe-Smith, A., \& Hinshaw, S. (2006). Linkages between child abuse and attention-deficit/hyperactivity disorder in girls: Behavioral and social correlates. Child Abuse \& Neglect, 30, 1239-1255. doi: 10.1016/j.chiabu.2006.04.008 
Endo, T., Sugiyama, T., \& Someya, T. (2006). Attention-deficit/hyperactivity disorder and dissociative disorder among abused children. Psychiatry and Clinical Neurosciences, 60, 434-438. doi: 10.1111/j.1440-1819.2006.01528.x

Fergusson, D., \& Horwood, L. (1999). Prospective childhood predictors of deviant peer affiliations in adolescence. Journal of Child Psychology and Psychiatry, 40, 581-592. doi: $10.1111 / 1469-7610.00475$

Ford, J., Wasser, T., \& Connor, D. (2011). Identifying and determining the symptomseverity associated with polyvictimization among psychiatrically impaired children in the outpatient setting. Child Maltreatment, 16, 16-226. doi: 10.1177/1077559511406109

Ford, J., Connor, D., \& Hawke, J. (2009). Complex trauma among psychiatrically impaired children: A cross-sectional, chart-review study. Journal of Clinical Psychiatry, 70, 1155-1163. doi: 10.4088/JCP.08m04783

Hechtman, L. (2005). ADHD. In B. Sadock \& V. Sadock (Eds.), Comprehensive textbook of psychiatry (8th edn), (pp. 3183-3198). Philadelphia: Lippincott, Williams \&Wilkins.

Hepworth, I. \& McGowan, L. (2013). Do mental health professionals enquire about childhood sexual abuse during routine mental health assessment in acute mental health settings? A substantive literature review. Journal of Psychiatric and Mental Health Nursing, 20, 473-483. doi: 10.1111/j.1365-2850.2012.01939.x

Kisiel, C., Fehrenback, T., Small, L. \& Lyons, J. (2009). Assessment of complex trauma exposure, responses, and service needs among children and adolescents in child welfare. Journal of Child and Adolescent Trauma, 2, 143-160. doi: $10.1080 / 19361520903120467$ 
Longden, E., Sampson, M., \& Read, J. (2016). Childhood adversity and psychosis: Generalised or specific effects? Epidemiology and Psychiatric Sciences. doi: $10.1017 / \mathrm{S} 204579601500044 \mathrm{X}$

Maniglio, R. (2015). Significance, nature, and direction of the association between child sexual abuse and conduct disorder: A systematic review. Trauma, Violence, \& Abuse, 16, 241-257. doi: 10.1177/1524838014526068

Maguire, S., Williams, B., Naughton, A., Cowley, L., Tempest, V. Mann, M., ... Kemp, A. (2015). A systematic review of the emotional, behavioural and cognitive features exhibited by school-aged children experiencing neglect or emotional abuse. Child: Care, Health and Development, 41, 641-653. doi: 10.1111/cch.12227

McLaren, J., \& Brown, R. (1989). Childhood problems associated with abuse and neglect. Canada's Mental Health, 37(3), 1-6. Retrieved from http://psycnet.apa.org/psycinfo/1990-14924-001

McLeer, S., Deblinger, E., Henry, D., \& Orvaschel, H. (1992). Sexually abused-children at high-risk for posttraumatic-stress-disorder. Journal of the American Academy of Child and Adolescent Psychiatry, 3, 875-879. doi: http://dx.doi.org/10.1097/00004583199209000-00015

Meller, S., Kuperman, K., McCullough, C., Shaffer, A. (2016). Adverse effects of childhood emotional maltreatment on child behavioral outcomes. Journal of Aggression. Maltreatment \& Trauma, 2, 127-144. doi:10.1080/10926771.2016.1101034

Merry, S., \& Andrews, L. (1994). Psychiatric status of sexually abused children 12 months after disclosure of abuse. Journal of the American Academy of Child and Adolescent Psychiatry, 33, 939-944. doi: http://dx.doi.org/10.1097/00004583-199409000-00002 Muskett, C. (2014). Trauma-informed care in inpatient mental health settings: A review of 
the literature. International Journal of Mental Health Nursing, 23, 51-59. doi: 10.1111/inm.12012

Nigg, J., \& Craver, L. (2014). Commentary: ADHD and social disadvantage: An inconvenient truth? Journal of Child Psychology and Psychiatry, 55, 446-447. doi: 10.1111/jcpp. 12237

Ouyang, L., Fang, X., Mercy, J., Perou, R., \& Grosse, S. (2008). Attentiondeficit/hyperactivity disorder symptoms and child maltreatment: A population-based study. Journal of Pediatrics, 153, 851-856. doi: 10.1016/j.jpeds.2008.06.002

Perry, B. (2013). Brief: Reflections on childhood, trauma and society. Houston: Child Trauma Academy Press.

Posner, J., Eilenberg, J., Friedman, J. \& Fullilove, M. (2008). Quality and use of trauma histories obtained from psychiatric outpatients: A ten-year follow-up. Psychiatric Services, 59, 318-321. doi: 10.1176/appi.ps.59.3.318

Read, J. (2013). Childhood adversity and psychosis: From heresy to certainty. In J. Read \& J. Dillon (Eds.), Models of madness: Psychological, social and biological approaches to psychosis, (2 $\left.{ }^{\text {nd }} \mathrm{edn}\right),($ pp. 249-275). London: Routledge.

Read, J., Fosse, R., Moskowitz, A. \& Perry, B. (2014). The traumagenic neurodevelopmental model of psychosis revisited. Neuropsychiatry, 4, 65-79. doi: 10.2217/npy.13.89

Read, J., Hammersley, P. \& Rudegeair, T. (2007). Why, when and how to ask about abuse. Advances in Psychiatric Treatment, 13, 101-110. doi: 10.1192/apt.bp.106.002840

Read, J., Agar, K., Argyle, N., \& Aderhold, V. (2003). Sexual and physical abuse during childhood and adulthood as predictors of hallucinations, delusions, and thought disorder. Psychology \& Psychotherapy: Theory, Research and Practice, 76, 1-22. doi: $10.1348 / 14760830260569210$ 
Read, J., Sampson, M., \& Critchley, C. (2016). Are mental health services getting better at responding to abuse, assault and neglect? Acta Psychiatrica Scandinavica. doi: 10.1111/acps. 12552

Rose, S., Freeman, C., \& Proudlock, S. (2012). Despite the evidence - why are we still not creating more trauma informed mental health services? Journal of Public Mental Health 11, 5-9. doi: http://dx.doi.org/10.1108/17465721211207266

Rossiter, A., Byrne, F., Wota, A., Nisar, Z., Ofuafor, T., Murray, I., ... Hallahan, B. (2015). Childhood trauma levels in individuals attending adult mental health services: An evaluation of clinical records and structured measurement of childhood trauma. Child Abuse \& Neglect, 44, 36-45. doi: 10.1016/j.chiabu.2015.01.001

Russell, G., Ford, T., Rosenberg, R., \& Kelly S. (2014). The association of attention deficit hyperactivity disorder with socioeconomic disadvantage: Alternative explanations and evidence. Journal of Child Psychology and Psychiatry, 55, 436-445. doi: $10.1111 /$ jcpp. 12170

Sadock, B., \& Sadock, V. (Eds.) (2005). Comprehensive textbook of psychiatry (8th edn.). Philadelphia: Lippincott Williams \& Wilkins.

Sadock, B., \& Sadock, V. (Eds.) (2014). Concise textbook of child and adolescent psychiatry. Philadelphia: Lippincott Williams \& Wilkins.

Stern, A., Lynch, D., Oates, R., O’Toole, B.., \& Cooney, G. (1995). Self-esteem, depression, behavior and family functioning in sexually abused-children. Journal of Child Psychology and Psychiatry and Allied Disciplines, 36, 1077-1089. doi: 10.1111/j.1469-7610.1995.tb01352.x

Teicher, M., \& Samson, J. (2016). Annual Research Review: Enduring neurobiological effects of childhood abuse and neglect. Journal of Child Psychology and Psychiatry. doi: $10.1111 /$ jcpp. 12507 
Webster, R. (2001). Symptoms and long-term outcomes for children who have been sexually assaulted. Psychology in the Schools, 38, 533-547. doi: 10.1002/pits.1041

Weinstein, D., Staffelbach, D., \& Biaggio, M. (2000). Attention-deficit hyperactivity disorder and posttraumatic stress disorder: Differential diagnosis in childhood sexual abuse. Clinical Psychology Review, 20, 359-378. doi:10.1016/S0272-7358(98)00107-X

Young, M., Read, J., Barker-Collo, S., \& Harrison, R. (2001). Evaluating and overcoming barriers to taking abuse histories. Professional Psychology: Research and Practice, 32, 407-414. doi: http://dx.doi.org/10.1037/0735-7028.32.4.407 


\section{Table 1}

Diagnoses and their symptom clusters

\begin{tabular}{|c|c|c|c|c|c|c|c|}
\hline ADHD & Inattentiveness & Hyperactivity & Impulsivity & & & & \\
\hline PTSD & Re-experiencing & $\begin{array}{l}\text { Avoidancel } \\
\text { numbing }\end{array}$ & Hyperarousal & & & & \\
\hline Psychosis & Hallucinations & Delusions & $\begin{array}{l}\text { Disorganised } \\
\text { speech }\end{array}$ & $\begin{array}{l}\text { Disorganised/ } \\
\text { catatonic } \\
\text { behaviour }\end{array}$ & $\begin{array}{l}\text { Negative } \\
\text { symptoms }\end{array}$ & & \\
\hline Conduct Disorder & $\begin{array}{l}\text { Aggression to } \\
\text { people/animals }\end{array}$ & $\begin{array}{l}\text { Destruction of } \\
\text { property }\end{array}$ & $\begin{array}{l}\text { Deceitfulness } \\
\text { or theft }\end{array}$ & $\begin{array}{l}\text { Serious rule } \\
\text { violation }\end{array}$ & & & \\
\hline $\begin{array}{l}\text { Oppositional } \\
\text { Defiant Disorder }\end{array}$ & $\begin{array}{l}\text { Noncompliant/ } \\
\text { defiant }\end{array}$ & Oppositional & & & & & \\
\hline Mood Disorders & Low mood & $\begin{array}{l}\text { Other } \\
\text { depressive } \\
\text { symptoms }\end{array}$ & $\begin{array}{l}\text { Emotional } \\
\text { dysregulation }\end{array}$ & Mania & & & \\
\hline Anxiety Disorders & $\begin{array}{l}\text { Excessive and } \\
\text { persistent worry }\end{array}$ & Phobia & Compulsions & Obsessions & $\begin{array}{l}\text { Panic } \\
\text { symptoms }\end{array}$ & $\begin{array}{l}\text { Separ- } \\
\text { ation } \\
\text { anxiety }\end{array}$ & $\begin{array}{l}\text { Social } \\
\text { anxiety }\end{array}$ \\
\hline Eating Disorders & $\begin{array}{l}\text { Restrictive } \\
\text { eating }\end{array}$ & $\begin{array}{l}\text { Compensatory } \\
\text { and purging } \\
\text { behaviour, }\end{array}$ & $\begin{array}{l}\text { Bingeing } \\
\text { behaviour }\end{array}$ & & & & \\
\hline $\begin{array}{l}\text { Learning } \\
\text { Disorders }\end{array}$ & $\begin{array}{l}\text { Mental } \\
\text { retardation }\end{array}$ & $\begin{array}{l}\text { Communication } \\
\text { problems }\end{array}$ & $\begin{array}{l}\text { Learning } \\
\text { difficulties }\end{array}$ & & & & \\
\hline $\begin{array}{l}\text { Aspergers } \\
\text { Syndrome }\end{array}$ & $\begin{array}{l}\text { Deficits in } \\
\text { social } \\
\text { interaction }\end{array}$ & $\begin{array}{l}\text { Qualitative } \\
\text { impairments in } \\
\text { communication }\end{array}$ & $\begin{array}{l}\text { Stereotypical } \\
\text { and repetitive } \\
\text { behaviour }\end{array}$ & & & & \\
\hline
\end{tabular}


Table 2

Frequencies of diagnoses

\begin{tabular}{|l|l|l|}
\hline Depression Not Otherwise Specified & 27 & $12.4 \%$ \\
\hline ADHD & 25 & $11.5 \%$ \\
\hline Adjustment Disorder & 22 & $10.1 \%$ \\
\hline Anxiety Disorder NOS & 21 & $9.7 \%$ \\
\hline Major Depressive Disorder & 13 & $6.0 \%$ \\
\hline Aspergers Syndrome & 13 & $6.0 \%$ \\
\hline Generalized Anxiety Disorder & 12 & $5.5 \%$ \\
\hline Dysthymia & 10 & $4.6 \%$ \\
\hline PTSD & 9 & $4.1 \%$ \\
\hline Social Anxiety Disorder & 8 & $3.7 \%$ \\
\hline Obsessive Compulsive Disorder & 7 & $3.2 \%$ \\
\hline Panic Disorder & 6 & $2.8 \%$ \\
\hline Learning Disorder & 6 & $2.8 \%$ \\
\hline Conduct Disorder & 6 & $2.8 \%$ \\
\hline Separation Anxiety Disorder & 5 & $2.3 \%$ \\
\hline Oppositional Defiant Disorder & 5 & $2.3 \%$ \\
\hline Psychosis (including Psychosis NOS & 5 & $2.3 \%$ \\
\hline and Schizophreniform Disorder) & & \\
\hline Substance Abuse/Dependence & 5 & $2.3 \%$ \\
\hline $\begin{array}{l}\text { Eating Disorder (including Bulimia, } \\
\text { Anorexia and ED NOS) }\end{array}$ & 5 & $2.3 \%$ \\
\hline Selective Mutism & 5 & $2.3 \%$ \\
\hline
\end{tabular}


Table 3

Significant relationships between childhood adversities and specific symptoms, and risk to self and others

\begin{tabular}{|c|c|c|c|c|c|c|c|c|c|c|}
\hline & $\begin{array}{l}\text { Mean } \\
\text { Number of } \\
\text { Adversities } \\
\end{array}$ & $\begin{array}{l}\text { Sexual } \\
\text { Abuse }\end{array}$ & $\begin{array}{l}\text { Emot. } \\
\text { Abuse }\end{array}$ & $\begin{array}{l}\text { Physic. } \\
\text { Abuse }\end{array}$ & $\begin{array}{l}\text { Domes. } \\
\text { Violen. }\end{array}$ & Neglect & Poverty & $\begin{array}{l}\text { Parent } \\
\text { Subst. } \\
\text { Abuse } \\
\end{array}$ & $\begin{array}{l}\text { Parent } \\
\text { Mental } \\
\text { Health } \\
\text { Problem } \\
\end{array}$ & Loss \\
\hline $\begin{array}{l}\text { (PTSD) } \\
\text { Re-experiencing }\end{array}$ & & $* *$ & & & & & & & & \\
\hline Hyperarousal & & $* * *$ & & & & & & & & \\
\hline $\begin{array}{l}\text { Avoidance/ } \\
\text { numbing }\end{array}$ & & & & & & & & & $* *$ & $* * *$ \\
\hline $\begin{array}{l}\text { (MOOD) } \\
\text { Low Mood }\end{array}$ & $* *$ & $* *$ & $* *$ & & & & & & & \\
\hline $\begin{array}{l}\text { Other } \\
\text { Depressive }\end{array}$ & $* * *$ & $*$ & $* * *$ & & & & & & & \\
\hline $\begin{array}{l}\text { Emotional } \\
\text { Dysregulation }\end{array}$ & & $* *$ & & & & & & & & \\
\hline Mania & $* *$ & & & & & & & & & \\
\hline $\begin{array}{l}\text { (ADHD) } \\
\text { Hyperactivity }\end{array}$ & & & & & $* *$ & & & & & \\
\hline $\begin{array}{l}\text { (CONDUCT } \\
\text { DISORDER) } \\
\text { Aggression }\end{array}$ & & & & & $*$ & & & & & \\
\hline Rule Violation & & & & $* *$ & & & & $* * *$ & & \\
\hline Deceipt/Theft & $* *$ & & & & & & & & & \\
\hline $\begin{array}{l}\text { (PSYCHOSIS) } \\
\text { Delusions }\end{array}$ & $* *$ & & & & & & & & & \\
\hline $\begin{array}{l}\text { Disorganised } \\
\text { Speech }\end{array}$ & $* * *$ & & & & & & & & & \\
\hline $\begin{array}{l}\text { Disorganised/ } \\
\text { Catatonic Behv. }\end{array}$ & & & & & & $*$ & & & & \\
\hline $\begin{array}{l}\text { Negative } \\
\text { Symptoms }\end{array}$ & $* * *$ & & & & & & $* *$ & & & \\
\hline $\begin{array}{l}\text { RISK TO } \\
\text { SELF }\end{array}$ & $* * *$ & & & & & & & & & \\
\hline $\begin{array}{l}\text { RISK TO } \\
\text { OTHERS }\end{array}$ & $*$ & & $*$ & & $*$ & & & & & \\
\hline
\end{tabular}

$*=\mathrm{p}<.01 ; * *=\mathrm{p}<.005 ; * * *=\mathrm{p}<.001$ 